\title{
Effect of Moringa oleifera Leaf Meal Supplementation on Growth Performance, Morphological Indexes, Antioxidant Status and Resistance to Streptococcus agalactiae of Nile Tilapia (Oreochromis niloticus)
}

\author{
Shijun Chen ${ }^{1, \#}$, Youming Jia ${ }^{1, \#}$, Weihua $\mathrm{Xu}^{1}$, Jin Peng ${ }^{1}$, Yuhui He ${ }^{1}$, Jijia Sun ${ }^{1}$, Qing \\ Pan ${ }^{1}$, Chaoxiong Peng ${ }^{3}$, Junjiang Yang ${ }^{3}$, Xiaoyang Chen ${ }^{2, *}$, Lian Gan ${ }^{1,3, *}$ \\ ${ }^{1}$ College of Marine Sciences, South China Agricultural University, Guangzhou, 510642, P.R. China. \\ ${ }^{2}$ State Key Laboratory for Conservation and Utilization of Subtropical Agro-Introduction Bioresources, South China \\ Agricultural University, Guangzhou, 510642, P.R. China. \\ ${ }^{3}$ Foshan DBN Huilin Aquaculture Science \& Technology Co. Ltd, Foshan, 524500, P.R. China. \\ \#These authors share the first authorship.
}

\section{Article History}

Received Jun 14, 2020

Accepted Nov 17, 2020

First Online Nov 18, 2020

\section{Corresponding Author}

Tel.: +8602087571321

E-mail: ganlian@scau.edu.cn; xychen@scau.edu.cn

\section{Keywords}

Antibacterial

Antioxidant

Lipotropic effect

Moringa oleifera

Oreochromis niloticus

\begin{abstract}
An 8-week feeding trial was conducted to evaluate the effect of Moringa oleifera leaf meal (MOLM) on growth performance, antioxidant status and morphological indexes in Nile tilapia (Oreochromis niloticus). Resistance to Streptococcus agalactiae was also assessed based on a $192 \mathrm{~h}$ challenge experiment after feeding trial. Fish (initial mean weight $4.05 \pm 0.05 \mathrm{~g}$ ) were held in 21 tanks (volume $300 \mathrm{~L}, 30 \mathrm{fish} /$ tank), with triplicate treatment groups being fed to apparent satiation three times each day on practical diets adding different levels of $\operatorname{MOLM}(0,0.1,0.5,2,5,10$ and 20\%). Sampling procedure was performed after $24 \mathrm{~h}$ of fasting. Growth metrics showed no significant differences among groups. Whole-body lipid content, viscerosomatic index and intraperitoneal fat ratio were decreased as dietary MOLM levels increasing. Total superoxide dismutase (T-SOD) and reduced glutathione content (GSH) were significantly influenced by MOLM. Moreover, the lowest cumulative mortality rate (CMR) after challenge experiment was noted in $10 \%$ group. Based on CMR and quadratic regression analysis of liver GSH content, it was concluded that dietary MOLM levels of $8.15-10.00 \%$ may be beneficial for enhancing resistance to $S$. agalactiae infection. Our results suggest that the maximum additive amount of MOLM reached $20 \%$ under the condition of the present study.
\end{abstract}

\section{Introduction}

Soybean meal is a vital plant protein source and widely used as a feed ingredient for aquaculture species due to its relatively high nutritional value and digestibility (Puycha et al., 2017). However, owing to its unstable prices and market supply, it is necessary to identify other plant resources to substitute dietary soybean meal (Kasiga \& Lochmann, 2014). Moringa oleifera, a member of the family Moringaceae, is a fastgrowing plant widely distributed in the tropics and subtropics (Richter et al., 2003). It is initially treated as a plant with medical value and utilized as an alternative food source for resistance malnutrition in developing countries (Rweyemamu et al., 2015; Anwar et al., 2007). Due to its leaf protein content reached $26 \%$, stable market supply and contained some essential amino acids including methionine, cysteine, tryptophan and lysine (Makkar \& Becker, 1996; Oyeyinka \& Oyeyink, 2018), it has been treated as a plant protein source and applied into diet of some fish species, such as sea bass (Lates calcarifer) (Ganzon-Naret, 2014), African Catfish (Clarias gariepinus) (Hlophe \& Moyo, 2014a), Nile tilapia (Oreochromis niloticus) (Bbole, Mumba, Mupenda, \& Kefi, 2016) and Bocourti's catfish (Pangasius bocourti) (Puycha et al., 2017). Previous studies have shown that the maximum amount of $M$. oleifera leaf added to the diet was varied with fish species, and its value did not 
exceed $12 \%$ under the promise of not negatively affecting the growth (Richter et al., 2003; Puycha et al., 2017). Moreover, fish meal, as the most urgently replaced protein source by producers, occupied an important proportion (31-40\%) in the formula of these studies. However, in the case of low dietary fish meal, the maximum amount of $M$. oleifera leaves added in the diet is unclear.

Phytochemicals, such as carotenoids, vitamin C, vitamin E, sterols, glycosides, alkaloids, flavonoids and moringine, have been reported to exist in various organs of M. oleifera (Sreelatha et al., 2011). Some of constituents mentioned above are considered to be beneficial for treating diseases, such as inflammation, cardiovascular and liver diseases (Limaye et al., 1995; Rao \& Misra, 1998; Gopalakrishnan et al., 2016). Antioxidant property of $M$. oleifera was also found by evaluating oxidative stability of oil extracted from $M$. oleifera leaves (Anwar et al., 2007; Park et al., 2011). Streptococcus agalactiae infection has been recorded to cause some fish diseases, such as meningitis, sepsis, ascites and anorexia, which finally resulting in high mortality (Su et al., 2016). It also negatively influenced antioxidant capacity of fish (Du et al., 2020). Importantly, S. agalactiae is the main pathogen causing tilapia streptococcus disease in China. Whether the antioxidant and antibacterial properties of $M$. oleifera can help tilapia resist $S$. agalactiae infection is unknown. Besides, fat-degrade effect was observed in finisher pigs due to supplementation of $M$. oleifera leaf meal (Mukumbo et al., 2014). To our knowledge, previous studies have mostly focused on effects of different forms and levels of $M$. oleifera on fish growth. However, research on fat-degrade effect and resistance to pathogen infection is limited. Therefore, the objective of the present research was to investigate the effect of graded levels of dietary MOLM on growth performance, morphometry indices, serum biochemical indexes, antioxidant enzymes activities and resistance to $S$. agalactiae infection in Nile tilapia.

\section{Materials and Methods}

\section{Preparation of $M$. oleifera Leaf Meal and Experimental Diets}

The method for making $M$. oleifera leaf meal was in accordance with that of Nkukwana et al. (2014) with minor modification. Fresh, green and undamaged mature $M$. oleifera leaves, obtained from South China Agricultural University and air-dried during the day with no direct sunlight exposure, with constant turning over to prevent fungal growth, were finely ground in a laboratory grinder and stored at room temperature before feed formulation. The nutrient and amino acid composition of MOLM were consistent with study reported by Chen et al. (2018) and shown as follows: crude protein, $26.6 \%$; crude lipid, $4.3 \%$; crude ash, $10.8 \%$; arginine, $1.5 \%$; histidine, $0.6 \%$; lysine, $1.6 \%$; phenylalanine, $1.6 \%$; leucine, $2.3 \%$; isoleucine, $1.2 \%$; methionine, $0.1 \%$; valine, $1.4 \%$; alanine, $1.7 \%$; glycine, $1.4 \%$; proline, $1.2 \%$; serine, $1.1 \%$; threonine, $1.2 \%$. The amino acid composition of MOLM was analyzed by a Hitachi L-8900 automatic amino acid analyzer. The proximate analysis of diets and MOLM was based on the procedures of the Association of Official Analytical Chemists (AOAC) (1997) standard methods. Moisture was determined by putting samples in an oven at $105^{\circ} \mathrm{C}$ until constant weight. The methods and instruments used to determine crude protein, crude lipid and ash content of dried diets were consistent with those reported by Gan et al. (2013). Crude protein $(N \times 6.25)$ was determined by the Kjeldahl method after acid digestion using an Auto Kjeldahl System (1030-Autoanalyzer, Tecator, Sweden). Crude lipid was tested by the ether-extraction method using a Soxtec System HT (Soxtec System HT6, Tecator, Sweden). Ash content was determined by incineration in a muffle furnace at $550{ }^{\circ} \mathrm{C}$ for $24 \mathrm{~h}$.

The formulation and composition analysis of the experimental diets is given in Table 1. Fish meal, soybean meal, canola meal and wheat flour were used as dietary protein sources. Soybean oil was utilized as dietary lipid sources. The basal diet was formulated to contain about $30.1 \%$ crude protein and $6.4 \%$ crude lipid. Seven practical diets were formulated to contain MOLM at levels of $0,0.1,0.5,2,5,10$ and $20 \%$ diets. Various proportions of ingredients mentioned above were balanced with wheat flour. The method of manufacturing diet was consistent with the methods described by Gan et al. (2013). The dry ingredients were weighed and well-mixed by a Hobart mixer (A-200T Mixer bench Model unit, Russell Food Equipment, Ottawa, ON, Canada). Lipids and water were then added and thoroughly mixed. The $1.5 \mathrm{~mm}$ and $2.5 \mathrm{~mm}$ diameter pellets were cold-extruded using a pelletizer (Institute of Chemical Engineering, South China University of Technology, Guangdong, China), then airdried to approximately $10 \%$ moisture, and saved at $20^{\circ} \mathrm{C}$ until used.

\section{Fish Management}

Healthy juvenile Nile tilapia, obtained from a local commercial hatchery (Guangdong Tilapia Fry Farm, China), were reared in the feeding facility at the South China Agricultural University (Guangzhou, China) and fed to apparent satiation with a commercial diet (Zhuhai Shihai Feed Co., Ltd., China), and then acclimated to laboratory condition for two weeks. Afterwards, a total of 630 fish (initial mean weight $4.05 \pm 0.05 \mathrm{~g}$ ) were randomly distributed into $21300-\mathrm{L}$ tanks (inside diameter $80 \mathrm{~cm}$, height $60 \mathrm{~cm}$ ) at the end of the acclimatization period, and each dietary treatment was randomly assigned to triplicate tanks. Fish was fed the respective diets to apparent satiation three times a day $(8: 00,12: 00$ and $17: 00)$ at a feeding rate of 3 to $5 \%$ body weight during the 8 -week feeding trial, and the amount 
Table 1. Formulation and proximate composition of the experimental diets (\% dry matter)

\begin{tabular}{|c|c|c|c|c|c|c|c|}
\hline \multirow{2}{*}{ Ingredients } & \multicolumn{7}{|c|}{ Dietary addition levels of MOLM } \\
\hline & $0 \%$ & $0.1 \%$ & $0.5 \%$ & $2 \%$ & $5 \%$ & $10 \%$ & $20 \%$ \\
\hline Fish meal & 3.5 & 3.5 & 3.5 & 3.5 & 3.5 & 3.5 & 3.5 \\
\hline Soybean meal & 32.00 & 31.95 & 31.75 & 31.00 & 29.48 & 26.95 & 21.90 \\
\hline Canola meal & 22 & 22 & 22 & 22 & 22 & 22 & 22 \\
\hline Wheat flour & 34.30 & 34.25 & 34.07 & 33.38 & 32.03 & 29.77 & 25.23 \\
\hline Moringa oleifera Lam (leaf meal) & 0 & 0.1 & 0.5 & 2 & 5 & 10 & 20 \\
\hline Soybean oil & 4.50 & 4.50 & 4.48 & 4.42 & 4.29 & 4.08 & 3.66 \\
\hline Monocalcium phosphate $\mathrm{Ca}\left(\mathrm{H}_{2} \mathrm{PO}_{4}\right)_{2}$ & 2 & 2 & 2 & 2 & 2 & 2 & 2 \\
\hline Premix ${ }^{1}$ & 1 & 1 & 1 & 1 & 1 & 1 & 1 \\
\hline DL-methionine $(\geq 98 \%)^{2}$ & 0.30 & 0.30 & 0.30 & 0.30 & 0.30 & 0.30 & 0.31 \\
\hline Choline chlorine (50\%) & 0.40 & 0.40 & 0.40 & 0.40 & 0.40 & 0.40 & 0.40 \\
\hline \multicolumn{8}{|l|}{ Proximate composition (\% dry matter) } \\
\hline Crude protein & 30.1 & 29.7 & 29.6 & 29.6 & 29.5 & 29.4 & 29.0 \\
\hline Crude lipid & 6.4 & 6.4 & 6.3 & 6.4 & 6.3 & 6.2 & 6.0 \\
\hline
\end{tabular}

Soybean meal, canola meal, fish meal, wheat flour and soybean oil were purchased from Zhuhai Shihai Feed Corporation Ltd.

Choline chlorine was purchased from Guangzhou Chengyi Aquatic Technology Ltd. ${ }^{1}$ premix including (mg/kg premix): Zn, 7000; Fe, 6000; Mn, 750; Co, 100; I, 120; Cu, 500; Se, 35; thiamine, 600; vitamin B2, 850; vitamin A, 300,000 IU; vitamin E, 2,500; vitamin D3, 80,000 IU; vitamin K3, 400; vitamin B6, 600; vitamin C, 8,500; biotin, 12; calcium pantothenate, 1,500; nicotinamide, 3,000; inositol, 4,000 (Guangzhou Chengyi Aquatic Technology Ltd, Guangzhou, China). ${ }^{2}$ DL-methionine consists of $98.5 \%$ DL-methionine (Novus International Inc.).

of feed fed everyday was recorded. During the feeding experiment, fish were weighed every two weeks, and the amount of the diet was adjusted according to fish weight. Fish was reared in indoor recirculation system tanks with continuous aeration. Uneaten feeds and fecal waste were removed by siphoning. The uneaten feeds were used to calculate amount of feed intake (FI) after drying. Water temperature and dissolved oxygen concentration were monitored daily using a portable oxygen meter (Taiwan, China, AZ8403), and water quality parameters were monitored using a HachTM water quality test kit. Water temperature and $\mathrm{pH}$ were kept at $29.0^{\circ} \mathrm{C}$ (average) and $7.4 \pm 0.2$, respectively. Total ammonia nitrogen was lower than $0.05 \mathrm{mg} / \mathrm{L}$, and dissolved oxygen was kept above $7.0 \mathrm{mg} / \mathrm{L}$. Natural lightdark cycle was employed during the experiment, and the photoperiod was 12-h light/12-h dark.

\section{Sample Collection and Chemical Analysis}

All procedures implemented for fish followed handling guidelines of South China Agricultural University. At the end of the feeding trial, fish were starved for $24 \mathrm{~h}$ and anesthetized with MS-222 (Shanghai Reagent Corporation, China) before weighing and sampling. It is important to note that the fish used in the $S$. agalactiae infection experiment were not anesthetized. Four fish from each tank were randomly gathered for the analysis of the whole-body composition. Another six fish per tank were randomly selected for obtaining body length and weight of individual whole body, viscera, liver and intraperitoneal fat, and then calculating condition factor (CF), viscerosomatic index (VSI), hepatosomatic index (HSI) and intraperitoneal fat index (IPF). In addition, four fish from each tank were randomly sampled for collecting blood and liver. The serum was separated by centrifuging at $850 \mathrm{~g}$ for $10 \mathrm{~min}$ at $4{ }^{\circ} \mathrm{C}$ and then stored at $-80^{\circ} \mathrm{C}$ for testing serum biochemical indexes and antioxidant enzyme. Liver tissues were immediately dissected and placed into liquid nitrogen, and then stored at $-80^{\circ} \mathrm{C}$ until used. Liver tissues were homogenized in the proportion of $1: 9(\mathrm{w} / \mathrm{v})$ of ice-cold physiological saline solution and then centrifuged at $3,550 \mathrm{~g}$ for $20 \mathrm{~min}$ at $4^{\circ} \mathrm{C}$. After that, the supernatant was collected and kept at $-80^{\circ} \mathrm{C}$ for determining antioxidant enzyme. The proximate analysis of fish whole-body composition was based on the procedures of the AOAC (1997) standard methods.

\section{Streptococcus agalactiae Infection Experiment}

S. agalactiae challenge experiment was carried out according to the method reported by Yi et al. (2014) with some modifications. S. agalactiae THN strain was provided by the disease lab in College of Marine Sciences of South China Agricultural University (Guangzhou, China). The concentration of $S$. agalactiae infection was $0.1 \times 10^{7} \mathrm{CFU} / \mathrm{mL}$ obtained from a preliminary trial. Briefly, the bacteria were cultivated in $\mathrm{BHI}$ broth and incubated in a shaker $(200 \mathrm{rpm})$ incubator at $2^{\circ} \mathrm{C}$ overnight and the concentration was adjusted to $0.1 \times 10^{7} \mathrm{CFU} / \mathrm{mL}$. At the end of the feeding trial, fish were starved for $24 \mathrm{~h}$, and then 10 fish from each tank without anesthesia were selected and each fish was intraperitoneally injected with $0.1 \mathrm{~mL}$ culture. Each treatment group had triplicates, and mortality was monitored every $12 \mathrm{~h}$ for up to $192 \mathrm{~h}$. All dead fish were immediately removed from the tanks.

\section{Serum Biochemical Indexes and Antioxidant Parameters Assays}

The content of low-density lipoprotein (LDL), highdensity lipoprotein (HDL), triacylglycerol (TAG), cholesterol (CHO), total protein (TP) and activities of 
alanine aminotransferase (ALT) and aspartate aminotransferase (AST) were measured by an automatic biochemical analyser (Hitachi 7170A; DAICHI, Tokyo, Japan). The serum was sent to a professional hospital for detection of indexes mentioned above (Traditional Chinese Medicine Hospital of Guangdong Province, China). The content of reduced glutathione (GSH) and activity of total superoxide dismutase (T-SOD) were determined by using commercial kits (Nanjing Jiancheng Bioengineering Institute, Nanjing, China). GSH can react with dithiobisnitrobenzoicacid (DTNB) to form a yellow compound, which can be used for colorimetric quantitative determination of GSH content at $405 \mathrm{~nm}$. In addition, T-SOD activity was determined by its ability to inhibit superoxide anion generated by a xanthine and xanthine oxidase reaction system. Absorbance of indexes mentioned above was tested by a microplate spectrophotometer Epoch (BioTek, USA).

\section{Statistical Analysis}

Results were presented as means \pm standard error (standard error of the mean, SEM). One-way analysis of variance (ANOVA) followed by Duncan's multiple range test was selected to assess significant differences among all groups by using SPSS Statistic 20.0 software (SPSS Inc., Chicago, IL, USA). The Kruskal-Wallis ANOVA test (non-parametric test) was utilized when inhomogeneous variance appeared, followed by pairwise comparisons using Kruskal-Wallis. Probability value of $\mathrm{P}<0.05$ was considered statistically significant. In addition, quadratic regression method was used to evaluate the optimum level of MOLM supplementation in Nile tilapia according to Chen et al. (2019). Pearson correlation coefficient $(r)$ was used to evaluate the correlation between dietary MOLM levels and morphological parameters.

\section{Results}

\section{Growth Performance, Morphometry Indices and Whole-Body Composition}

Growth performance indexes of Nile tilapia are given in Table 2. FBW, WG, SGR, FI, FCR and SR did not vary considerably among experimental groups $(P>0.05)$.

As shown in Figure 1, CF and IPF were markedly reduced as dietary MOLM levels increasing $(P<0.05)$, and the lowest value was found in the $20 \%$ group. Although VSI showed a decreasing trend with the increase of dietary MOLM levels, there was no significant difference among groups $(P>0.05)$. In addition, HSI showed no significant difference among all groups $(P>0.05)$. According to Pearson correlation coefficient, a significantly negative correlation was existed between these parameters and dietary MOLM levels.

Whole-body composition is given in Table 3 . Whole-body lipid content was markedly decreased with dietary MOLM levels increasing $(P<0.05)$. Significant reduction of ash content was observed in $5 \%$ and $10 \%$ groups when compared with other groups (except for the $2 \%$ group) $(P<0.05)$. However, no significant differences were noted in crude protein and moisture among all treatments $(\mathrm{P}>0.05)$.

\section{Serum Biochemical Indexes before S. agalactiae Infection}

Serum biochemical indexes of Nile tilapia fed experimental diets are present in Figure 2. Dietary MOLM supplementation significantly reduced $\mathrm{HDL}$ in $0.1 \%$ and $2 \%$ groups and increased TAG in $0.5 \%$ group as compared with $0 \%$ group $(\mathrm{P}<0.05)$. TP, $\mathrm{CHO}$ and AST in $10 \%$ group was markedly lower than that of $0.5 \%$ group

Table 2. Effect of dietary MOLM levels on growth performance of Nile tilapia fed experimental diets

\begin{tabular}{|c|c|c|c|c|c|c|c|c|}
\hline \multirow{2}{*}{ Parameters } & \multicolumn{7}{|c|}{ Dietary addition levels of MOLM } & \multirow{2}{*}{$P$-value } \\
\hline & $0 \%$ & $0.1 \%$ & $0.5 \%$ & $2 \%$ & $5 \%$ & $10 \%$ & $20 \%$ & \\
\hline IBW & $4.02 \pm 0.05$ & $4.06 \pm 0.02$ & $4.07 \pm 0.00$ & $4.06 \pm 0.01$ & $4.06 \pm 0.01$ & $4.02 \pm 0.05$ & $4.06 \pm 0.03$ & 0.786 \\
\hline FBW & $74.7 \pm 4.59$ & $77.0 \pm 3.19$ & $77.3 \pm 1.18$ & $75.6 \pm 0.67$ & $69.0 \pm 2.93$ & $71.4 \pm 2.28$ & $70.9 \pm 1.55$ & 0.245 \\
\hline WG & $1686.9 \pm 73.3$ & $1738.8 \pm 45.7$ & $1674.5 \pm 58.8$ & $1620.5 \pm 49.7$ & $1485.8 \pm 89.4$ & $1582.4 \pm 67.0$ & $1622.1 \pm 39.7$ & 0.191 \\
\hline SGR & $5.21 \pm 0.09$ & $5.25 \pm 0.07$ & $5.26 \pm 0.03$ & $5.22 \pm 0.01$ & $5.05 \pm 0.08$ & $5.14 \pm 0.08$ & $5.11 \pm 0.05$ & 0.244 \\
\hline $\mathrm{FI}$ & $7.60 \pm 0.20$ & $7.24 \pm 0.10$ & $7.21 \pm 0.16$ & $7.05 \pm 0.01$ & $6.98 \pm 0.09$ & $7.31 \pm 0.07$ & $7.73 \pm 0.31$ & 0.053 \\
\hline FCR & $1.07 \pm 0.03$ & $1.00 \pm 0.01$ & $1.02 \pm 0.02$ & $1.02 \pm 0.02$ & $1.05 \pm 0.02$ & $1.06 \pm 0.01$ & $1.11 \pm 0.03$ & 0.059 \\
\hline$S R$ & $95.6 \pm 1.13$ & $96.7 \pm 1.93$ & $92.2 \pm 2.22$ & $91.1 \pm 2.94$ & $92.22 \pm 1.11$ & $94.5 \pm 1.08$ & $98.9 \pm 1.11$ & 0.077 \\
\hline
\end{tabular}

IBW, initial mean body weight (g/fish);

FBW, final mean body weight (g/fish);

WG, weight gain $(\%)=100 \times(\mathrm{FBW}-\mathrm{IBW}) / \mathrm{IBW}$;

$\mathrm{SGR}$, specific growth rate $(\% /$ day $)=100 \times[\operatorname{Ln}(\mathrm{FBW})-\operatorname{Ln}(\mathrm{IBW})] / 56$ days;

$\mathrm{FCR}$, feed conversion rate=feed consumed ( $\mathrm{g}$, dry weight) / weight gain ( $\mathrm{g}$, wet weight);

$\mathrm{FI}$, feed intake $(\% / \mathrm{d})=$ grams of dry feed consumed $\times 100 / \sqrt{(\text { IBW } \times \text { Initial fish number }) \times(\mathrm{FBW} \times \text { Final fish number }+ \text { Dead fish body weight })} / 56$ days

(The equation was consistent with the report of Gan et al. (2013)).

SR, survival rate $(\%)=100 \times$ (final number of fish) / (initial number of fish)

Data are presented as mean $\pm \operatorname{SEM}(n=3)$. Values with different letters in the same line indicate significant differences $(P<0.05)$. 


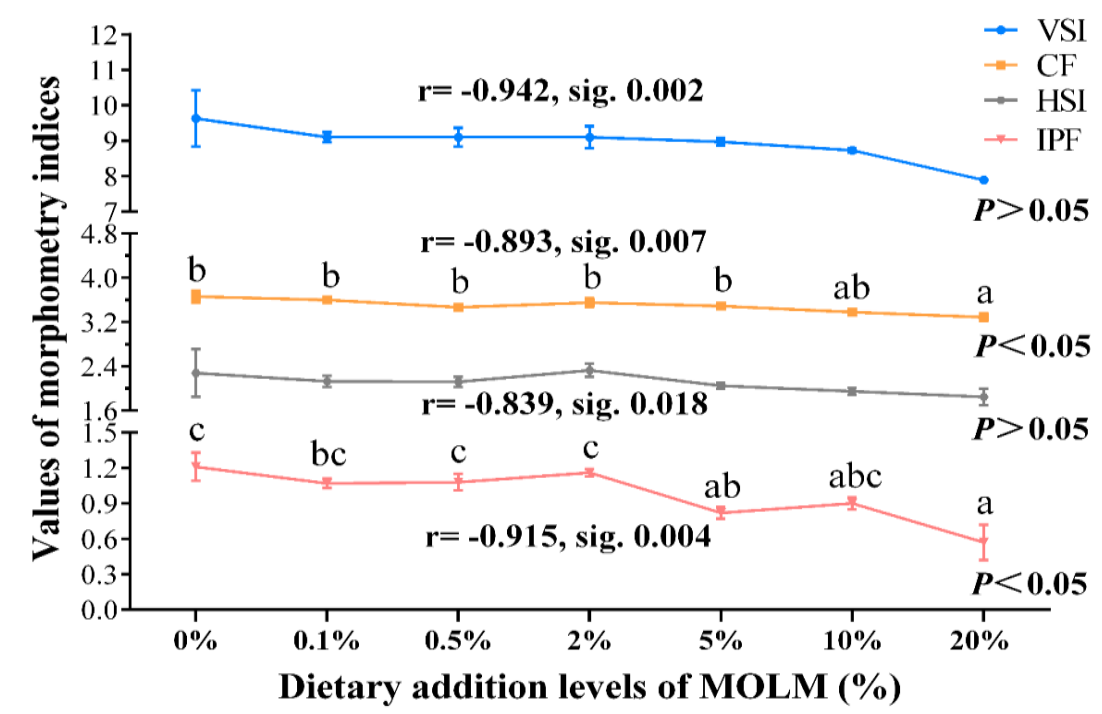

Figure 1. Morphometry indices of Nile tilapia fed experimental diets for 8 -week. Data are presented as mean \pm SEM $(n=3)$. The line with different letters indicates significant differences $(P<0.05)$. $r$, Pearson correlation coefficient; sig., significance (for correlation analysis). CF, condition factor $\left(\mathrm{g} / \mathrm{cm}^{3}\right)=100 \times$ body weight $(\mathrm{g}) /$ body length $\left(\mathrm{cm}^{3}\right)$; VSI, viscerosomatic index $(\%)=100 \times($ visceral weight) / (whole body weight); HSI, Hepatosomatic index (\%)=100x(liver weight) / (whole body weight); IPF, intraperitoneal fat ratio $(\%)=100 \times$ (intraperitoneal fat weight) / (whole body weight).

Table 3. Effect of dietary MOLM levels on body composition of Nile tilapia fed experimental diets for 8-week

\begin{tabular}{|c|c|c|c|c|c|c|c|c|}
\hline \multirow{2}{*}{ Parameters } & \multicolumn{7}{|c|}{ Dietary addition levels of MOLM } & \multirow{2}{*}{$P$-value } \\
\hline & $0 \%$ & $0.1 \%$ & $0.5 \%$ & $2 \%$ & $5 \%$ & $10 \%$ & $20 \%$ & \\
\hline \multicolumn{9}{|c|}{ Whole body (\% wet weight) } \\
\hline Moisture & $69.8 \pm 0.84$ & $69.0 \pm 0.43$ & $68.1 \pm 0.38$ & $69.4 \pm 0.43$ & $70.8 \pm 0.95$ & $70.2 \pm 0.44$ & $69.7 \pm 1.03$ & 0.235 \\
\hline Crude protein & $16.3 \pm 0.40$ & $16.0 \pm 0.54$ & $16.2 \pm 0.06$ & $16.5 \pm 0.45$ & $15.8 \pm 0.43$ & $15.8 \pm 0.86$ & $15.7 \pm 0.44$ & 0.897 \\
\hline Crude lipid & $9.05 \pm 0.53^{b c}$ & $9.52 \pm 0.22^{c}$ & $9.20 \pm 0.31^{c}$ & $8.60 \pm 0.29^{b c}$ & $7.88 \pm 0.13^{\mathrm{ab}}$ & $8.43 \pm 0.27^{b c}$ & $7.16 \pm 0.56^{a}$ & 0.005 \\
\hline Ash & $3.77 \pm 0.11^{b}$ & $3.79 \pm 0.03^{b}$ & $3.81 \pm 0.08^{b}$ & $3.60 \pm 0.12^{\mathrm{ab}}$ & $3.41 \pm 0.04^{\mathrm{a}}$ & $3.39 \pm 0.15^{\mathrm{a}}$ & $3.86 \pm 0.15^{b}$ & 0.027 \\
\hline
\end{tabular}

Data are presented as mean \pm SEM $(n=3)$. Values with different letters in the same line indicate significant differences $(P<0.05)$.

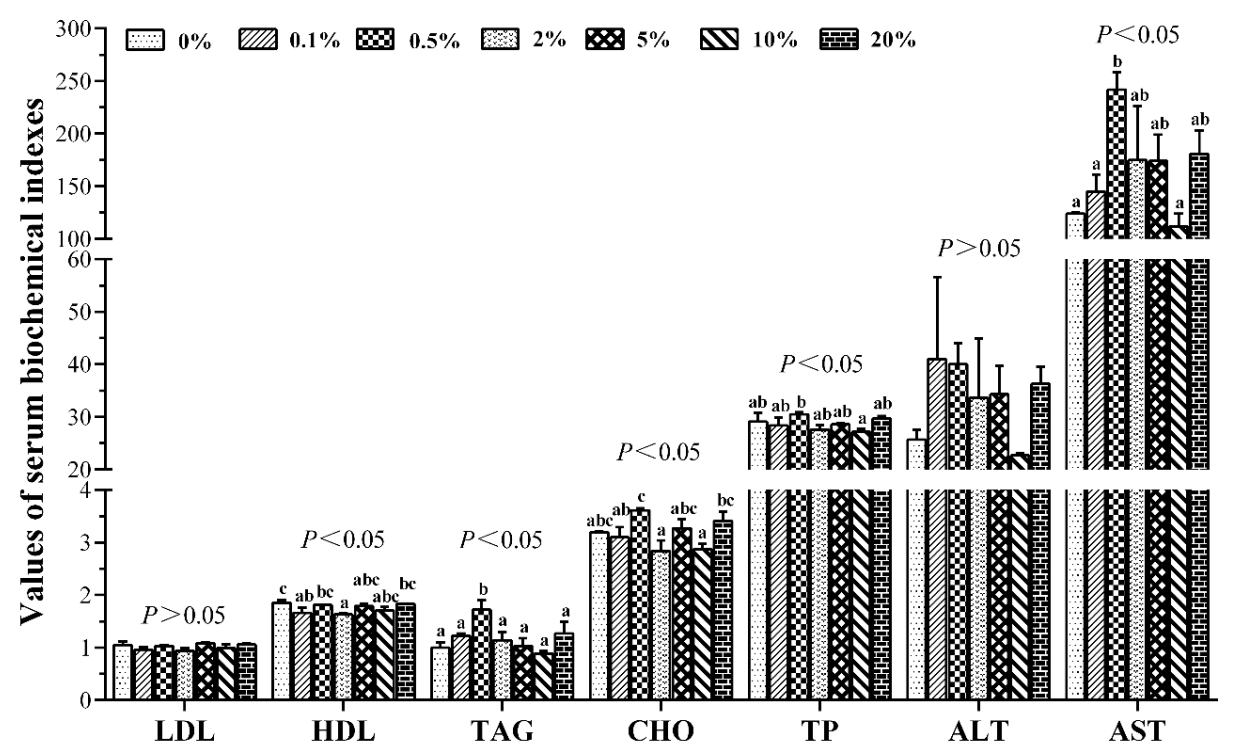

Figure 2. Serum biochemical indexes of Nile tilapia fed experimental diets for 8-week. Data are presented as mean $\pm S E M(n=3)$. The column with different letters indicates significant differences $(P<0.05)$. LDL (low-density lipoprotein, mmol/L), HDL (high-density lipoprotein, $\mathrm{mmol} / \mathrm{L}$ ), TAG (triacylglycerol, $\mathrm{mmol} / \mathrm{L}$ ), $\mathrm{CHO}$ (cholesterol, $\mathrm{mmol} / \mathrm{L}$ ), TP (total protein, $\mathrm{g} / \mathrm{L}$ ), ALT (alanine transaminase, $\mathrm{U} / \mathrm{L}$ ) and AST (aspartate aminotransferase, $\mathrm{U} / \mathrm{L}$ ). 
$(P<0.05)$. However, ALT and LDL showed no significant difference among all groups $(P>0.05)$.

\section{Cumulative Mortality Rate after $192 \mathrm{~h}$ S. agalactiae Challenge}

As shown in Table 4, cumulative mortality rate (CMR) in $0 \%, 0.5 \%, 5 \%, 10 \%$ and $20 \%$ groups was increased with dietary MOLM levels increasing when stress time before $72 \mathrm{~h}$, and maintained thereafter. $0.1 \%$ and $2 \%$ groups showed a similar trend, but the deadline for continuously increased CMR was changed to $120 \mathrm{~h}$. After 192 h S. agalactiae challenge, the highest CMR was discovered in $0.1 \%$ group, and the lowest CMR was observed in $10 \%$ group.

\section{T-SOD and GSH in Serum and Liver of Nile tilapia before and after $192 \mathrm{~h}$ S. agalactiae Challenge}

T-SOD activity and GSH content in serum and liver of Nile tilapia before and after $S$. agalactiae challenge are given in Figure 3.

Before challenge, $0.1 \%, 5 \%, 10 \%$ and $20 \%$ groups had higher serum T-SOD activities when opposed to $0 \%$ group $(\mathrm{P}<0.05)$. Dietary MOLM supplementation significantly raised liver GSH content in $10 \%$ group and reduced the index in $0.5 \%$ group $(P<0.05)$. After challenge, serum T-SOD activity in $10 \%$ and $20 \%$ groups and serum GSH content in $5 \%$ group were considerably higher than that in $0 \%$ group $(P<0.05) .0 .1 \%, 2 \%$ and $5 \%$ groups had higher liver GSH content when opposed to $20 \%$ group $(P<0.05)$. However, the rest of parameters showed no significant difference among all treatments $(P>0.05)$. The optimal level of dietary MOLM supplementation was estimated to be $8.15 \%$ diet based on liver GSH content after 192 h S. agalactiae challenge using a quadratic regression method $\left(y=-0.3053 x^{2}+4.9765 x+45.066, \quad R^{2}=0.6164, \quad P=0.001\right)$ (Figure 4).

\section{Discussion}

In this study, the results showed that the growth of fish fed with higher levels of MOLM (10\% and $20 \%$ ) was not considerably different with those of fish fed with control diet, suggesting that the maximum amount of MOLM added to diet is $20 \%$ without negative impact on growth. This value was greater than the results (maximum additional amount ranged from $7.27 \%$ to $10.0 \%$ ) obtained from other fish species (Yuangsoi \& Masumoto, 2012; Ganzon-Naret, 2014; Hlophe \& Moyo, 2014b; Puycha et al., 2017). Even for the same species, the results are different. Richter et al. (2003) found that high levels of dietary MOLM (exceeding 12\%) led to the decrease of WG and $\mathrm{FI}$ in Nile tilapia. The main reason for these differences may be the composition of the formula. In most of the experiments mentioned above, the addition of fish meal exceeded $22 \%$, while the addition in this experiment was only $3.5 \%$. Besides, the processing methods of leaves may be another factor contributing to the difference. In the study of Richter et al. (2003), M. oleifera leaves were freeze-dried and its phytic acid and saponins content is $2.3 \%$ and $6.4 \%$, respectively. However, for air-dried leaves, the values were changed to $0.1 \%$ and $1.2 \%$, respectively (Madalla et al., 2013). Significantly, phytic acid and saponin have been reported to be antinutritional factors contributing to the poor growth performance in some fish species (Spinelli et al., 1983; Dongmeza et al., 2006). The present study suggested that under the condition of low fish meal, the addition of MOLM in the diet can reach $20 \%$ in Nile tilapia.

Oduro-Owusu et al. (2015) reported that supplementation of $5 \%$ MOLM was markedly reduced back fat thickness in pigs. It seems that $M$. oleifera has an effect on lowering body lipid content. In the present study, IPF and whole-body lipid content were significantly decreased as dietary MOLM levels increasing. Similar results related to whole-body lipid content were also observed in the research conducted by Richter et al. (2003). Reduction of body lipid content may be linked to poor feed intake which led to starvation, and finally mobilized reserved body lipid to meet energy requirements for body physical functions (Madalla et al., 2013). However, feed intake in this experiment did not show a continuous decline with the increase of dietary MOLM levels. Feed intake did not seem to be the main cause of the decline in body lipid content. The decreased lipid content may be attributed to hypolipidaemic activity of bioactive agents (such as alkaloids and $\beta$-sitosterol) contained in the M. oleifera (Ghasi et al., 2000; Atsukwei et al., 2014). In addition, saponins existed in $M$. oleifera leaves may inhibit pancreatic lipase activity, which finally delayed intestinal absorption of dietary lipid (Han et al., 2000). Further research is still needed to explore the potential mechanism of lowering body lipid.

Serum cholesterol ( $\mathrm{CHO}$ ), high-density lipoprotein cholesterol (HDLC), low-density lipoprotein cholesterol (LDLC) and triacylglycerol (TAG) have been reported to be useful indicators for assessing lipid metabolism as well as predisposition of the heart to atherosclerosis and its associated coronary heart diseases (Yakubu et al., 2008). Atsukwei et al. (2014) reported that ethanol leaf extract of $M$. oleifera were markedly increased serum HDLC concentration and reduced total $\mathrm{CHO}$ and TAG concentrations in rats. The decrease of serum $\mathrm{CHO}$ in some MOLM-supplemented groups was also observed in the present study. $\beta$-sitosterol, as one of the main cholesterol-reducing components of the M. oleifera leaf, can reduce cholesterol levels by inhibiting cholesterol absorption in the intestines (Bordia \& Verma, 1998). Another way for lowering $\mathrm{CHO}$ was related to the function of LDLC which could carry cholesterol from the liver to the blood stream (Rana et al., 2007). Similar trends of LDL and CHO seem to support the second view. In addition, chlorogenic acid and moringine contained in M. oleifera have been confirmed to decrease serum $\mathrm{CHO}$ 
Table 4. Cumulative mortality rate of Nile tilapia treated with different dietary MOLM levels after $192 \mathrm{~h}$ S. agalactiae infection.

\begin{tabular}{|c|c|c|c|c|c|c|c|c|}
\hline \multirow{2}{*}{ Time } & \multicolumn{7}{|c|}{ Dietary addition levels of MOLM } & \multirow{2}{*}{$P$-value } \\
\hline & $0 \%$ & $0.1 \%$ & $0.5 \%$ & $2 \%$ & $5 \%$ & $10 \%$ & $20 \%$ & \\
\hline $24 \mathrm{~h}$ & $3.33 \pm 3.3^{\mathrm{a}}$ & $20.0 \pm 0.0^{b}$ & $13.3 \pm 3.3^{\mathrm{ab}}$ & $6.67 \pm 3.3^{\mathrm{ab}}$ & $0.00 \pm 0.0^{\mathrm{a}}$ & $0.00 \pm 0.0^{\mathrm{a}}$ & $3.33 \pm 3.3^{\mathrm{a}}$ & 0.021 \\
\hline $48 \mathrm{~h}$ & $23.3 \pm 3.3$ & $46.7 \pm 13.3$ & $26.7 \pm 16.7$ & $16.7 \pm 8.8$ & $13.3 \pm 8.8$ & $0.00 \pm 0.0$ & $16.7 \pm 3.3$ & 0.136 \\
\hline $72 \mathrm{~h}$ & $33.3 \pm 3.3$ & $46.7 \pm 13.3$ & $33.3 \pm 23.3$ & $20.0 \pm 11.5$ & $20.0 \pm 10.0$ & $3.33 \pm 3.3$ & $20.0 \pm 5.8$ & 0.238 \\
\hline $96 \mathrm{~h}$ & $33.3 \pm 3.3$ & $46.7 \pm 13.3$ & $33.3 \pm 23.3$ & $20.0 \pm 11.5$ & $20.0 \pm 10.0$ & $3.33 \pm 3.3$ & $20.0 \pm 5.8$ & 0.238 \\
\hline $120 \mathrm{~h}$ & $33.3 \pm 3.3$ & $50.0 \pm 15.3$ & $33.3 \pm 23.3$ & $23.3 \pm 8.8$ & $20.0 \pm 10.0$ & $3.33 \pm 3.3$ & $20.0 \pm 5.8$ & 0.199 \\
\hline $144 \mathrm{~h}$ & $33.3 \pm 3.3$ & $50.0 \pm 15.3$ & $33.3 \pm 23.3$ & $23.3 \pm 8.8$ & $20.0 \pm 10.0$ & $3.33 \pm 3.3$ & $20.0 \pm 5.8$ & 0.199 \\
\hline $168 \mathrm{~h}$ & $33.3 \pm 3.3$ & $50.0 \pm 15.3$ & $33.3 \pm 23.3$ & $23.3 \pm 8.8$ & $20.0 \pm 10.0$ & $3.33 \pm 3.3$ & $20.0 \pm 5.8$ & 0.199 \\
\hline $192 \mathrm{~h}$ & $33.3 \pm 3.3$ & $50.0 \pm 15.3$ & $33.3 \pm 23.3$ & $23.3 \pm 8.8$ & $20.0 \pm 10.0$ & $3.33 \pm 3.3$ & $20.0 \pm 5.8$ & 0.199 \\
\hline
\end{tabular}

Data are mean $\pm \operatorname{SEM}(n=3)$. Values with different letters in the same line indicate significant differences $(P<0.05)$.

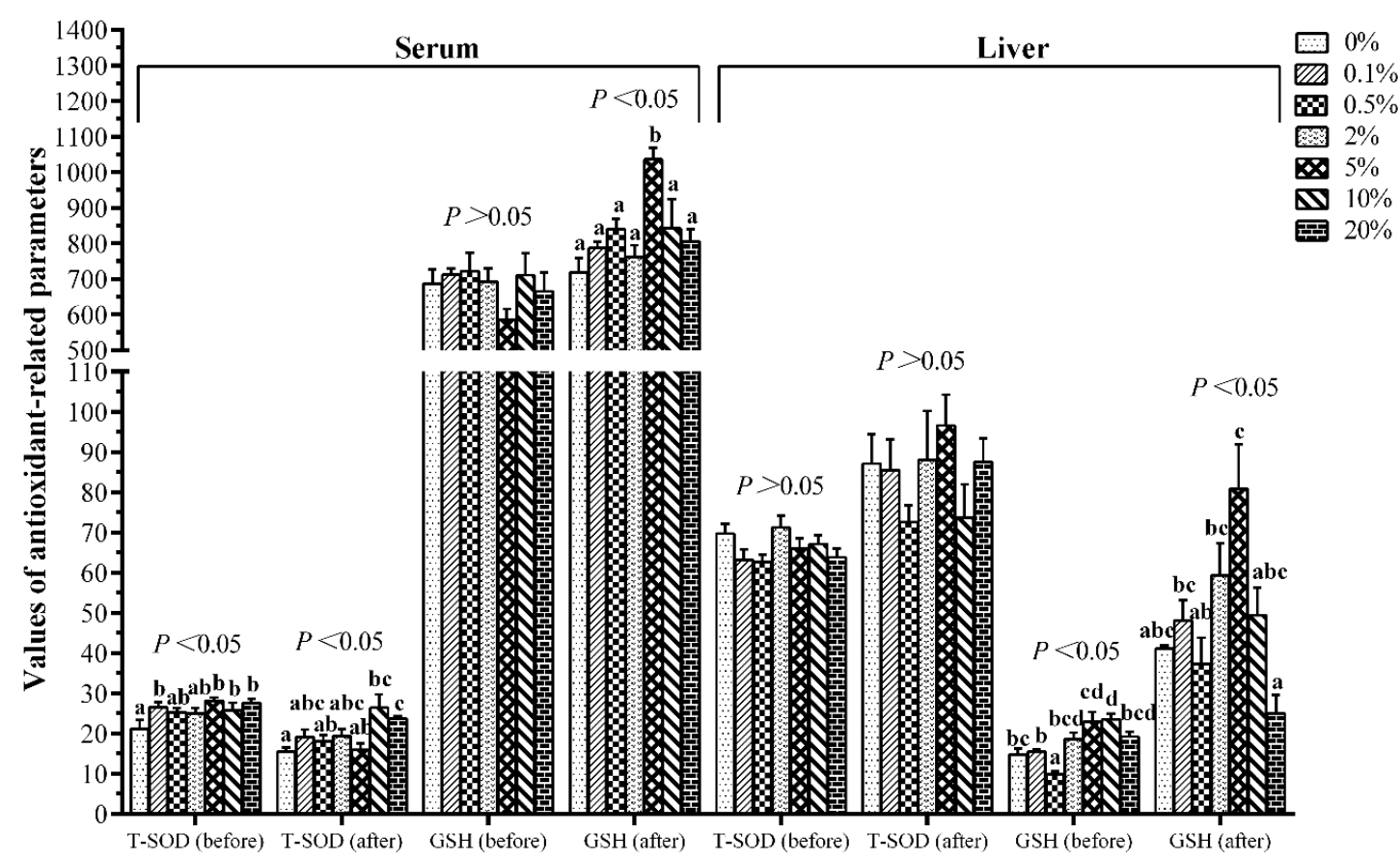

Figure 3. Activities of T-SOD and GSH in serum and liver of Nile tilapia treated with different dietary M. oleifera levels before and after $192 \mathrm{~h} \mathrm{~S}$. agalactiae infection. Results are presented as the mean $\pm \operatorname{SEM}(n=3)$. The column with different letters indicates significant differences $(P<0.05)$. Serum, T-SOD (total superoxide dismutase, $U / \mathrm{mL}$ ), GSH (reduced glutathione, $\mu \mathrm{mol} / \mathrm{L}$ ); Liver, T-SOD (U/mgprot), GSH ( $\mu \mathrm{mol} / \mathrm{gprot})$.

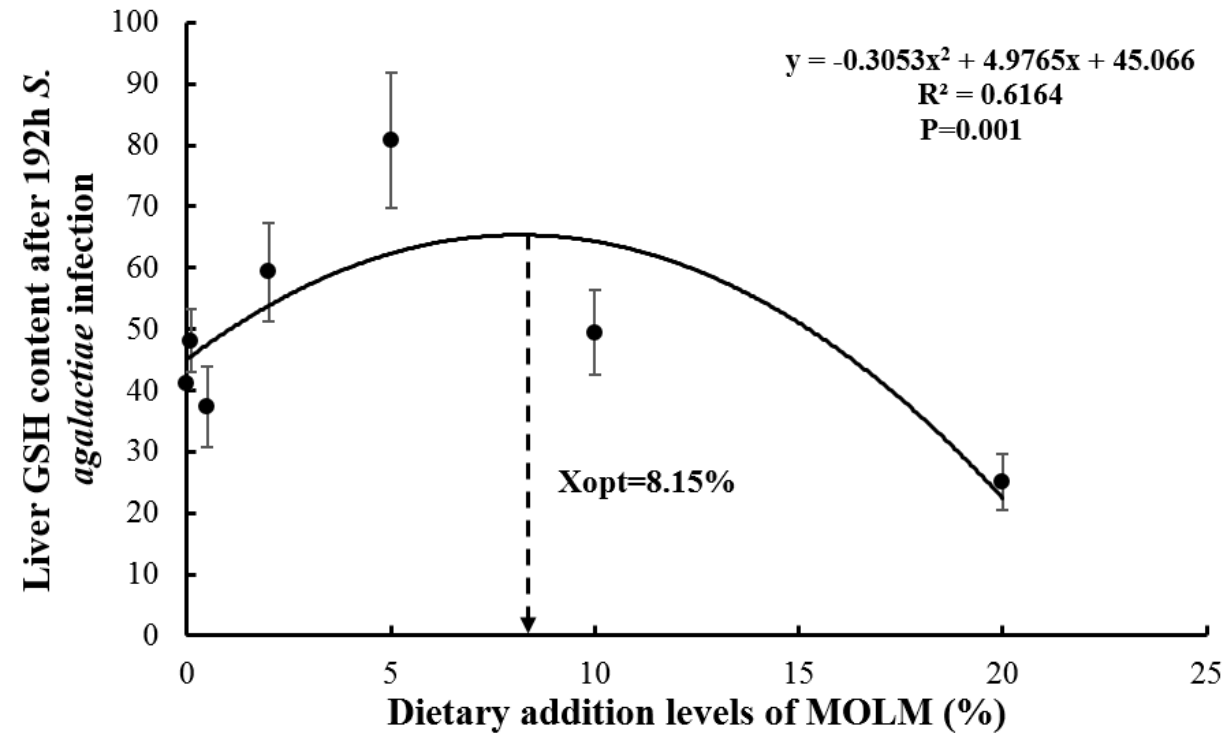

Figure 4. Estimation of optimal dietary MOLM levels for Nile tilapia using the quadratic regression method. 
(Cho et al., 2010). These results may suggest that the reduction of cholesterol in Nile tilapia was influenced by several factors. Significant increment of TAG was observed in $0.5 \%$ group as compared with other experimental groups, which was inconsistent with the study in rat and may be related to increased lipolysis (Atsukwei et al., 2014), suggesting that M. oleifera may exert different effects on TAG in rat and Nile tilapia.

Generally, AST and ALT are existed in liver with large quantities and high levels of these enzymes in serum may indicate hepatic dysfunction and damage (Soumendra et al., 2010). In our study, MOLM supplementation enhanced serum AST and ALT activities, which was similar with the study in rat that methanolic extract from $M$. oleifera leaves enhanced these enzymes activities (Oyagbemi et al., 2013). Sharma et al. (2002) reported that $\mathrm{HgCl}_{2}$ caused an increase in serum AST and ALT activities, which may be related to change of permeability of the plasma membrane. The increase of serum AST and ALT activities in the present research might be related to the increase of permeability in the plasma membrane caused by MOLM, and then led to leakage of these enzymes into the blood stream. The present study may suggest that MOLM influenced the liver structure of Nile tilapia.

The healthy development of China's aquaculture industry has been plagued by outbreaks of diseases. $S$. agalactiae, as a member of a family of bacteria that affect the health of fish, is common in tilapia farming (Dong et al., 2015). Due to the disadvantages of antibiotics against bacterial infection, more and more people focus on the application of herbal medicine (Ataguba et al., 2018). Some herbal extracts, such as extracts of Piper betle and Sophora flavescens, have been reported to be beneficial for resisting $S$. agalactiae infection (Wu et al., 2013; Ataguba et al., 2018). Similar result was also observed in the present study. More importantly, adding $10 \%$ MOLM was the best in fighting bacterial infection. Based on in vitro antimicrobial screening methods, Busani et al. (2012) found that the acetone extract of $M$. oleifera leaves exhibited antibacterial activities against some pathogens (such as Escherichia coli and Enterobacter cloace). High antioxidant and antimicrobial activities shown in $M$. oleifera were related to the presence of vitamin $E$, ascorbic acid, flavonoids, phenolics and carotenoids (Busani et al., 2012; Jayawardana et al., 2015; Das et al., 2012; Qwele et al., 2013). The reason why MOLM reduced mortality rate after $192 \mathrm{~h} S$. agalactiae challenge in this research seems to be explained in these studies, but the potential mechanism is still unclear. Previous study showed that $M$. oleifera extract could reduce lipid peroxidation caused by antitubercular drug treatment in rats (Kumar \& Pari, 2003). Gupta et al. (2007) also demonstrated that M. oleifera seed powder could protect mouse from oxidative stress caused by arsenic. These results suggest that $M$. oleifera may participate in regulation of antioxidant status. Antioxidant enzymes, prevented biological macromolecules from oxidative injury, are considered to be one of the most important components of the body's antioxidant system (Fontagné-Dicharry et al., 2014). SOD plays a vital role in protecting cells against reactive oxygen species (ROS) by coverting superoxide anions to hydrogen peroxide $\left(\mathrm{H}_{2} \mathrm{O}_{2}\right)$ (Qwele et al., 2013). Increment of liver SOD activity was observed in diabetic rats treated with $M$. oleifera when compared with the untreated group (Jaiswal et al., 2013). Similar result was observed in part of MOLM-supplemented groups after 192 h S. agalactiae infection. In addition, GSH has been reported to be an antioxidant in maintaining thiol-redox status and detoxicating of exogenous and endogenous reactive molecules (Oyedemi et al., 2010). Antitubercular drug treatment regimens may lead to serious side effect-liver disease (Mahashar \& Prabhudesai, 1991). The decrease in GSH content was observed in rats administered with an antitubercular drug. However, in rats co-treated with $M$. oleifera leaf extract, GSH level was increased, suggesting the protective role of $M$. oleifera. Similarly, dietary MOLM supplementation increased liver GSH content after pathogen infection. MOLM may have some beneficial role in improving antioxidant capacity, thereby decreasing mortality rate after $S$. agalactiae infection. Based on CMR and quadratic regression analysis of liver GSH content after 192 h S. agalactiae challenge, the optimal level of dietary MOLM supplementation was estimated to be $8.15-10.00 \%$.

\section{Conclusion}

This study demonstrated that $M$. oleifera leaf meal can be used as a feed ingredient and replace some proportion of dietary soybean meal. It also suggested that the maximum additive amount of MOLM was $20 \%$ under the conditions of this study. Moreover, dietary MOLM supplementation decreased body lipid. Appropriate level of MOLM supplementation may have a beneficial role in raising resistance to $S$. agalactiae infection and improving antioxidant status. Based on the results of the present study, optimum level of MOLM supplementation was estimated to be $8.58-10.00 \%$ diet in Nile tilapia with better pathogen resistance.

\section{Acknowledgement}

The research was supported by Guangdong Marine Economy Promotion Projects (MEPP) Fund (GDOE [2019] A26), Guangdong Provincial Special Fund for Modern Agriculture Industry Technology Innovation Teams (2019KJ150), Department of Agriculture and Rural Affairs of Guangdong Province, Guangdong Forestry Science Technology and Innovation Commission (Grant No. 2018KJCX001) and Project of Department of Ocean and Fishery of Guangdong Province, China (A201701C03). 


\section{References}

Anwar, F., Latif, S., Ashraf, M., \& Gilani, A.H. (2007). Moringa oleifera: a food plant with multiple medicinal uses. Phytotherapy Research, 21, 17-25. https://doi.org/10.1002/ptr.2023

Association of Official Analytical Chemists (AOAC) (1997). Official Methods of Analysis of Official Analytical Chemists International, sixteenth ed., Association of Official Analytical Chemists, Arlington, VA.

Atsukwei, D., Eze, E.D., Adams, M.D., Adinoyi, S.S., \& Ukpabi, C.N. (2014). Hypolipidaemic effect of ethanol leaf extract of Moringa oleifera Lam. in experimentally induced hypercholesterolemic wistar rats. International Journal of Nutrition and Food Sciences, 3, 355-360. https://doi.org/10.11648/j.ijnfs.20140304.28

Ataguba, G.A., Dong, H.T., Rattanarojpong, T., Senapin, S., \& Salin, K.R. (2018). Piper betle leaf extract inhibits multiple aquatic bacterial pathogens and in vivo Streptococcus agalactiae infection in Nile tilapia. Turkish Journal of Fisheries and Aquatic Sciences, 18, 671-680. http://doi.org/10.4194/1303-2712-v18_5_03

Bbole, I., Mumba, C., Mupenda, N., \& Kefi, A.S. (2016). Analysis of growth performance and haematological parameters of Oreochromis niloticus fed on a varying diet of Moringa oleifera Lam. leaf meal as an additive protein source. International Journal of Fisheries and Aquaculture, 8, 105-111.

https://doi.org/10.5897/JJFA2016.0570

Bordia, A., \& Verma, S.K. (1998). Effect of Celastrus paniculatus wild oil (Bravobol) on blood lipids in patients of coronary. Antiseptic, 95, 112.

Busani, M., Julius, M.P., \& Voster, M. (2012). Antimicrobial activities of Moringa oleifera Lam leaf extracts. African Journal of Biotechnology, 11, 2797-2802. https://doi.org/10.5897/AJB10.686

Chen, B., Gao, L.L., \& Pan, Q. (2018). Woody forages effect the intestinal bacteria diversity of golden pompano Trachinotus ovatus. AMB Express, 8, 29. https://doi.org/10.1186/s13568-018-0550-2

Chen, S.J., Xie, S.W., Chen, M., Mi, Z.S., He, Q., Yang, F., Niu, J., Liu, Y.J., \& Tian, L.X. (2019). Hypoxia-induced changes in survival, immune response and antioxidant status of the Pacific white shrimp (Litopenaeus vannamei) fed with graded levels of dietary myo-inositol. Aquaculture Nutrition, 25, 518-528. https://doi.org/10.1111/anu.12877

Cho, A.S., Jeon, S.M., \& Kim, M.J. (2010). Chlorogenic acid and moriginine exhibit anti-obesity property and improves lipid metabolism in high-fat diet-induced-obese mice. Food and Chemical Toxicology, 48, 937-943. https://doi.org/10.1016/j.fct.2010.01.003

Das, A.K., Rajkumar, V., Verma, A.K., \& Swarup, D. (2012). Moringa oleifera leaves extract: a natural antioxidant for retarding lipid oxidation in cooked goat meat patties. International Journal of Food Science and Technology, 47, 585-591. https://doi.org/10.1111/j.1365-2621.2011.02881.x

Du, J.L., Cao, L.P., Jia, R., Gu, Z.Y., He, Q., Xu, P., Jeney, G., Ma, Y.Z., \& Yin, G.J. (2020). Analysis of Streptococcus agalactiae-induced liver injury in tilapia (Oreochromis niloticus). Aquaculture Research, 51, 1398-1405. https://doi.org/10.1111/are.14485

Dong, H.T., Nguyen, V.V., Le, H.D., Sangsuriya, P., Jitrakorn, S., Saksmerprome, V., \& Rodkhum, C. (2015). Naturally concurrent infections of bacterial and viral pathogens in disease outbreaks in cultured Nile tilapia (Oreochromis niloticus) farms. Aquaculture, 448, 427-435. http://dx.doi.org/10.1016/j.aquaculture.2015.06.027

Dongmeza, E., Siddhuraju, P., Francis, G., \& Becker, K. (2006). Effects of dehydrated methanol extracts of moringa (Moringa oleifera Lam.) leaves and three of its fractions on growth performance and feed nutrient assimilation in Nile tilapia (Oreochromis niloticus (L.)). Aquaculture, 261, 407-422.

https://doi.org/10.1016/j.aquaculture.2006.08.006

Fontagné-Dicharry, S., Lataillade, E., Surget, A., Larroquet, L., Cluzeaud, M., \& Kaushik, S. (2014). Antioxidant defense system is altered by dietary oxidized lipid in firstfeeding rainbow trout (Oncorhynchus mykiss). Aquaculture, 424425, 220-227.

https://doi.org/10.1016/j.aquaculture.2014.01.009

Francis, G., Makkar, H.P.S., \& Becker, K. (2001). Antinutritional factors present in plant-derived alternate fish feed ingredients and their effects in fish. Aquaculture, 199, 197-227. https://doi.org/10.1016/s0044-8486(01)00526-9

Gan, L., Liu, Y.J., Tian, L.X., Yue, Y.R., Yang, H.J., Liu, F.J., Chen, Y.J. \& Liang, G.Y. (2013). Effects of dissolved oxygen and dietary lysine levels on growth performance, feed conversion ratio and body composition of grass carp, Ctenopharyngodon idella. Aquaculture Nutrition, 19, 860-869. https://doi.org/10.1111/anu.12030

Ganzon-Naret, E.S. (2014). Utilization of Moringa oleifera leaf meals as plant protein sources at different inclusion levels in fish meal-based diets fed to Lates calcarifer. ABAH Bioflux, 6, 158-167.

http://www.abah.bioflux.com.ro/docs/2014.158-167.pdf

Ghasi S., Nwobodo, E., \& Ofili, J.O. (2000). Hypocholesterolemic effects of crude extract of leaf of Moringa oleifera Lam in high-fat diet fed Wister rats. Journal of Ethnopharmacology, 69, 21-25. https://doi.org/10.1016/s0378-8741(99)00106-3

Gopalakrishnan, L., Doriya, K., \& Kumar, D.S. (2016). Moringa oleifera: A review on nutritive importance and its medicinal application. Food Science and Human Wellness, 5, 49-56. https://doi.org/10.1016/j.fshw.2016.04.001

Gupta, R., Dubey, D.K., Kannan, G.M., \& Flora, S.J.S. (2007). Concomitant administration of Moringa oleifera seed powder in the remediation of arsenic-induced oxidative stress in mouse. Cell Biology International, 31, 44-56. https://doi.org/10.1016/j.cellbi.2006.09.007

Han, L.K., Xu, B.J., Kimura, Y., Zheng, Y., \& Okuda, H. (2000). Platycodi radix affects Ipid metabolism in mice with high fat diet-induced obesity. Journal of Nutrition, 130, 27602764. https://doi.org/10.1093/jn/130.11.2760

Hlophe S.N., \& Moyo, N.A.G. (2014a). Replacing fishmeal with Kikuyu grass and Moringa leaves: effects on growth, protein digestibility, histological and haematological parameters in Clarias gariepinus. Turkish Journal of Fisheries and Aquatic Sciences, 14, 795-806. https://doi.org/10.4194/1303-2712-v14_3_22

Hlophe, S.N., \& Moyo, N.A.G. (2014b). A comparative study on the use of Pennisetum clandestinum and Moringa oleifera as protein sources in the diet of the herbivorous Tilapia rendalli. Aquaculture International, 22, 12451262. https://doi.org/10.1007/s10499-013-9744-4

Jaiswal, D., Rai, P.K., Mehta, S., Chatterji, S., Shukla, S., Rai, D.K., Sharma, G., Sharma, B., khair, S., \& Watal, G. (2013). 
Role of Moringa oleifera in regulation of diabetesinduced oxidative stress. Asian Pacific Journal of Tropical Medicine, 6, 426-432. https://doi.org/10.1016/s19957645(13)60068-1

Jayawardana, B.C., Liyanage, R., Lalantha, N., Iddamalgoda, S., \& Weththasinghe, P. (2015). Antioxidant and antimicrobial activity of drumstick (Moringa oleifera) leaves in herbal chicken sausages. LWT-Food Science and Technology, 64, 1204-1208.

https://doi.org/10.1016/j.lwt.2015.07.028

Kasiga, T., \& Lochmann, R. (2014). Nutrient digestibility of reduced-soybean-meal diets containing Moringa or Leucaena leaf meals for Nile tilapia, Oreochromis niloticus. Journal of the World Aquaculture Society, 45, 183-191. https://doi.org/10.1111/jwas.12102

Kumar, N.A., \& Pari, L. (2003). Antioxidant action of Moringa oleifera Lam. (Drumstick) against antitubercular drugs induced lipid peroxidation in rats. Journal of Medicinal Food, 6, 255-259. https://doi.org/10.1089/10966200360716670

Limaye, D.A., Nimbkar, A.Y., Jain, R., \& Ahmed, M. (1995). Cardiovascular effects of the aqueous extract of Moringa pterygosperma. Phytotherapy Research, 9, 37-40. https://doi.org/10.1016/0044-8486(83)90153-9

Madalla, N., Agbo, N.W., \& Jauncey, K. (2013). Evaluation of aqueous extracted Moringa leaf meal as a protein source for Nile tilapia juveniles. Tanzania Journal of Agricultural Sciences, 12, 53-64.

https://www.ajol.info//index.php/tjags/article/view/10 2021

Mahashar, A.A., \& Prabhudesai, P.P. (1991). Hepatitis and antitubercular therapy. The Journal of the Association of Physicians of India, 39, 595-596.

https://pubmed.ncbi.nlm.nih.gov/1814871/

Makkar, H.P.S., \& Becker, K. (1996). Nutritional value and antinutritional components of whole and ethanol extracted Moringa oleifera leaf. Animal Feed Science and Technology, 63, 211-228. https://doi.org/10.1016/s0377-8401(96)01023-1

Mukumbo, F.E., Maphosa, V., Hugo, A., Nkukwana, T.T., Mabusela, T.P., \& Muchenje, V. (2014). Effect of Moringa oleifera leaf meal on finisher pig growth performance, meat quality, shelf life and fatty acid composition of pork. South African Journal of Animal Science, 44, 388400.

https://doi.org/10.4314/sajas.v44i4.9

Nkukwana, T.T., Muchenje, V., Masika, P.J., Hoffman, L.C., Dzama, K., \& Descalzo, A.M. (2014). Fatty acid composition and oxidative stability of breast meat from broiler chickens supplemented with Moringa oleifera leaf meal over a period of refrigeration. Food Chemistry, 142, 255-261.

https://doi.org/10.1016/j.foodchem.2013.07.059

Oduro-Owusu, A.D., Kagya-Agyemang, J.K., Annor, S.Y., \& Bonsu, F.R.K. (2015). Growth performance, carcass characteristics and economic efficiency of using graded levels of Moringa leaf meal in feeding weaner pigs. American Journal of Experimental Agriculture, 7, 190196. https://doi.org/10.9734/ajea/2015/15262

Oyagbemi, A.A., Omobowale, T.O., Azeez, I.O., Abiola, J.O., Adedokun, R.A.M., \& Nottidge, H.O. (2013). Toxicological evaluations of methanolic extract of Moringa oleifera leaves in liver and kidney of male Wistar rats. Journal of Basic and Clinical Physiology and Pharmacology, 24, 307312. https://doi.org/10.1515/jbcpp-2012-0061

Oyedemi, S.O., Bradley, G., \& Afolayan, A.J. (2010). In vivo and in vitro antioxidant activities of aqueous stem bark extract of Strychnos henningsii (Gilg). African Journal of Pharmacy and Pharmacology, 4, 70-78. https://doi.org/10.1016/j.freeradbiomed.2012.08.237

Oyeyinka, A.T., \& Oyeyink, S.A. (2018). Moringa oleifera as a food fortificant: Recent trends and prospects. Journal of the Saudi Society of Agricultural Sciences, 17, 127-136. https://doi.org/10.1016/j.jssas.2016.02.002

Park, E.J., Cheenpracha, S., Chang, L.C., Kondratyuk, T.P., \& Pezzuto, J.M. (2011). Inhibition of lipopolysaccharideinduced cyclooxygenase- 2 and inducible nitric oxide synthase expression by 4-[(2'-O-acetyl-a-Lrhamnosyloxy) benzyl]-isothiocyanate from Moringa oleifera. Nutrition and Cancer, 63, 971-982. https://doi.org/10.1080/01635581.2011.589960

Puycha, K., Yuangsoi, B., Charoenwattanasak, S., Wongmaneeprateep, S., Niamphithak, P., \& Wiriyapattanasub, P. (2017). Effect of moringa (Moringa oleifera) leaf supplementation on growth performance and feed utilization of Bocourti's catfish (Pangasius bocourti). Agriculture and Natural Resources, 51, 286291. https://doi.org/10.1016/j.anres.2017.10.001

Qwele, K., Hugo, A., Oyedemi, S.O., Moyo, B., Masika, P.J., \& Muchenje, V. (2013). Chemical composition, fatty acid content and antioxidant potential of meat from goats supplemented with Moringa (Moringa oleifera) leaves, sunflower cake and grass hay. Meat Science, 93, 455462. https://doi.org/10.1016/j.meatsci.2012.11.009

Rana, J.S., Nieuwdorp, M., Jukema, J.W., \& Kastelein, J.J. (2007). Cardiovascular metabolic syndrome-an interplay of, obesity, inflammation, diabetes and coronary heart disease. Diabetes, Obesity and Metabolism, 9, 218-232. https://doi.org/10.1111/j.1463-1326.2006.00594.x

Rao, K.S., \& Misra, S.H. (1998). Anti-inflammatory and antihepatotoxic activities of the rats of Moringa pterygosperma Geaertn. Indian Journal of Pharmaceutical Sciences, 60, 12-16. https://doi.org/10.1134/S1990519X13020120

Richter, N., Siddhuraju, P., \& Becker, K. (2003). Evaluation of the quality of (Moringa oleifera Lam.) leaf as an alternative protein source for Nile tilapia (Oreochromis niloliticus L.). Aquaculture, 217, 599-611. https://doi.org/10.1016/s0044-8486(02)00497-0

Rweyemamu, L.M., Yusuph, A., \& Mrema, G. (2015). Physical properties of extruded snacks enriched with soybean and moringa leaf powder. African Journal of Food Science and Technology, 6, 28-34. https://doi.org/10.14303/ajfst.2015.010

Soumendra, D., Abhijit, B., \& Shyamaprasad, C. (2010). Ameliorative effect of Livina, a polyherbal preparation on Diclofenacinduced liver injury: a comparison with Silymarin. Journal of Pharmacy Research, 3, 2794-2798. http://jprsolutions.info/article_detail.php?article_id=10 45

Spinelli, J., Houle, C.R., \& Wekell, J.C. (1983). The effect of phytates on the growth of rainbow trout (Salmo gairdneri) fed with purified diets containing varying quantities of calcium and magnesium. Aquaculture, 30, 71-83. https://doi.org/10.1016/0044-8486(83)90153-9

Sreelatha, S., Jeyachitra, A., \& Padma, P.R. (2011). Antiproliferation and induction of apoptosis by Moringa oleifera leaf extract on human cancer cells. Food and Chemical Toxicology, 49, 1270-1275. 
https://doi.org/10.1016/j.fct.2011.03.006

Su, Y.L., Feng, J., Li, Y.W., Bai, J.S., \& Li, A.X. (2016) Development of a quantitative PCR assay for monitoring Streptococcus agalactiae coolonization and tissue tropism in experimentally infected tilapia. Journal of Fish Diseases, 39, 229-238.

https://doi.org/10.1111/jfd.12358

Sharma, M.K., Kumar, M., \& Kumar, A. (2002). Ocimum sanctum aqueous leaf extract provides protection against mercury induced toxicity in Swiss albino mice. Indian Journal of Experimental Biology, 40, 1079-1082. https://pubmed.ncbi.nlm.nih.gov/12587743/

Wu, Y.R., Gong, Q.F., Fang, H., Liang, W.W., Chen, M., \& He, R.J. (2013). Effect of Sophora flavescens on non-specific immune response of tilapia (GIFT Oreochromis niloticus) and disease resistance against Streptococcus agalactiae. Fish \& Shellfish Immunology, 34, 220-227. http://dx.doi.org/10.1016/j.fsi.2012.10.020
Yakubu, M.T., Akanji, M.A., \& Oladiji, A.T. (2008). Alterations in serum lipid profile of male rats by oral administration of aqueous extract of Fadogia argrestis stem. Research Journal of Medicinal Plant, 2, 66-73. https://doi.org/10.3923/rjmp.2008.66.73

Yi, T., Li, Y.W., Liu, L., Xiao, X.X., \& Li, A.X. (2014). Protection of Nile tilapia (Oreochromis niloticus L.) against Streptococcus agalactiae following immunization with recombinant FbsA and $\alpha$-enolase. Aquaculture, 428-429, 35-40.

https://doi.org/10.1016/j.aquaculture.2014.02.027

Yuangsoi, B., \& Masumoto, T. (2012). Replacing moringa leaf (Moringa oleifera) partially by protein replacement in soybean meal of fancy carp (Cyprinus carpio). Songklanakarin Journal of Science and Technology, 34, 479-485.

http://rdo.psu.ac.th/sjstweb/journal/34-5/0475-339534-5-479-485.pdf 